\title{
ANALYSIS OF THE ASSOCIATION BETWEEN COMPETENCE AND PERFORMANCE-FOCUSING ON FARMERS AND EXTENSION WORKERS
}

\author{
${ }^{1}$ Sue-Ho Chae, ${ }^{2}$ Yoon-Doo Kim and ${ }^{3}$ Hae-Jin Lim \\ ${ }^{1}$ Department of Agrifood Economics, Konkuk University, Chungju-si, South Korea \\ ${ }^{2}$ Department of International Trade and Culture, \\ Konkuk University, (Konkuk University Eco-food Supply Institute), Chungju-si, South Korea \\ ${ }^{3}$ Department of Management Administration, Konkuk University, Seoul, South Korea
}

Received 2013-11-11; Revised 2013-12-14; Accepted 2014-01-04

\begin{abstract}
The purpose of this study is to investigate the association between the competence of farmers and extension workers and the performance of the agricultural organizations in which they are involved. To this end, 20 competences of farmers and agricultural extension workers (10 of each), based on preceding studies, were selected as the independent variables. The dependent variable was defined as the process performance of the agricultural organization. Control variables were also selected for each study model. A standardized questionnaire was administered to 83 farmers and to 88 extension workers. Based on the questionnaire results, a hierarchical multiple regression analysis was performed to relate the competence of farmers and extension workers to the performance of agricultural organizations. Of the competence attributes, "Customer Satisfaction" and four kinds of variables exhibited statistically significant positive results in the performance of the farmers group. A positive correlation was found in "Interpersonal" and four kinds of variables in the extension workers group. As the study identified attributes of competence that are positively correlated with organizational performance, the results can provide useful information to policy-makers in terms of performance development of agricultural organizations and the agricultural industry as a whole.
\end{abstract}

Keywords:Farmers, Competence, Agricultural Organization Performance, Hierarchical Multiple Regression, Extension Workers

\section{INTRODUCTION}

The Korean agricultural sector is facing a challenge stemming from rapid changes in both the domestic and international environments.

In Korea, most farms are family-owned. These small operations are not capable of implementing strategic plans, such as production cost cutting, although they face increasing difficulties in the local market. The liberalization of the agricultural market, accelerated by Free Trade Agreements (FTAs), also poses a threat to farmers.

An array of policies and measures has been instituted as part of the effort to overcome the challenges facing the agricultural sector. These attempts and other studies have primarily focused on improving the performance of agricultural organizations through the systematization of farmers. However, conflicts of interest among farmers and the free-rider problem remain barriers to the success of this systematization. Therefore, strengthening the competitiveness of farms through organizational activities remains difficult.

While the majority of studies have focused on strengthening individual management competence, few have addressed the relationship between individual competence and agricultural organizational performance in rural areas. Therefore, this study aims to determine the

Corresponding Author: Yoon-Doo Kim, Department of International Trade and Culture, Konkuk University,

(Konkuk University Eco-food Supply Institute), Chungju-si, South Korea 
association between the competence of farmers and extension workers and the performance of the agricultural organizations in which they are involved. In addition, by identifying attributes of competence that contribute to organizational performance, this study suggests new ways to improve the performance of agricultural organizations.

\section{MATERIALS AND METHODS}

\subsection{Previous Studies and the Analysis Method}

In this study, two study models were employed to determine the association between the competence of farmers and extension workers and the performance of agricultural organizations. Model 1 was designed for the farmers group and model 2 for the extension workers group.

A hierarchical multiple regression was performed to analyze the effects of the competences of participants on the performance of agricultural organizations while controlling variables that were likely to affect organizational performance.

Data were analyzed in the following manner using SPSSWIN 18.0. Firstly, Cronbach's alpha was used for each variable to ensure the internal consistency of the questionnaire used for the study. Secondly, a hierarchical multiple regression was performed to analyze the association between individual competence and organizational performance.

\subsection{Previous Studies}

We began by reviewing previous studies that had the same objective as this study. The study by Heo (2009) estimated the association between personal variables of job applicants and their sales performance. Its results revealed that education level, sales experience, knowledge, direction for energy and judgment have significant effects on sales performance.

Another study by Lee (2002) aimed to strengthen competent human resources to improve organizational performance using the competency assessment program Expert Consulting (Expert-CAP). This study analyzed both the current and future importance of 26 attributes of competence in five groups. The author asserted that competence is crucial to organizational performance and that competence-centered human resource management and development is necessary.

The study by Mu-Geun (1987) explored the relationship between the leadership of rural village leaders and the development of rural villages. Based on the leadership contingency model, abilities, attitude and role were identified as leadership elements for leaders of rural villages.

A study of Open Innovation Competence (Chatenier, 2009) proved a significant association between individual competence and team performance by collecting data via questionnaires and using hierarchical multiple regressions.

Churchill et al. (1976) built a study model to find the effects of individual, organizational and situational variables on the performance of salespersons. They found that motivation, role acknowledgment and technique were closely related to performance, although the level of significance varied with attitude and the capabilities of the salespersons.

Kim et al. (2013) examined which farmer competences correlated with improving the performance of their agricultural organizations. According to the results, the ability to manage, customer satisfaction, marketing and obtaining information have a positive relationship with the performance of an agricultural organization. However, they found that strategic thinking has a negative relationship with performance.

Tiraieyari et al. (2013) analyzed the attitude of extension workers in Malaysia to Sustainable Agricultural Practices (SAP). Their results revealed that extension workers have a positive attitude towards SAP concepts. They recommend establishing which of the extension worker attitudes have played a significant role in transferring information to the farm.

\subsection{Survey}

Model 1 included 83 farmers who had attended agricultural training. Model 2 included 88 extension workers. A structured questionnaire was administered to participants, in person, while controlling for variables that were believed to affect the performance of agricultural organizations. The questionnaire was constructed to measure the competence of farmers and extension workers and the performance of the organizations in which they were involved. It also contained items measuring the effects of control variables on the performance of agricultural organizations.

\subsection{Hierarchical Multiple Regression Analysis}

The purpose of hierarchical multiple regression models is to analyze the relationship between independent variables and dependent variables by including or controlling one or more variables that are likely to influence the dependent variable. 


\section{RESULTS}

\subsection{Establish the Variables}

Control, independent and dependent variables were defined for model 1 (Model 1 analyzed the association of farmers and the performance of agricultural organizations, with control variables) and model 2 (Model 2 analyzed the association of extension workers and the performance of agricultural organizations, with control variables) with reference to previous studies. Each variable was measured using a seven-point Likert scale. The variables used in model 1 and model 2 are shown in Table 1.

\subsection{Control Variables}

Control (or input) variables were defined as those that might affect the analysis process and computation. The variables "Farmers who have attended training" and "Atmosphere of the organization to which the farmers belong" were selected as control variables in model 1 .

We measured farmers' experience of training by "Attendance of training" and "Satisfaction with training". Organizational atmosphere was measured by "The systematization of farmers" and "The leadership in organizations", as farmers could not quantitative influence to be affiliated with himself in agricultural organization.

Model 2 included "Extension workers' training experience and satisfaction" and "The extent of systematization of farmers in the area where they worked" as control variables.

\subsection{Independent Variable}

In model 1, attributes of individual competence that can affect the performance of agricultural organizations were selected as independent variables. Competence is defined as the ability to carry out and complete tasks effectively.

In this study, attributes of competence include "customer satisfaction", "creativity", "practicability", "flexibility", "strategic thinking", "innovation", "understanding", "getting information", "marketing" and "management". Of these variables, "customer satisfaction", "creativity", "practicability", "flexibility" and "strategic thinking" were seen as subjective attributes, as they were not measurable.

The remaining attributes, including "getting information", "marketing" and "management", were considered to be objective variables.
"Customer satisfaction" is the ability to identify and satisfy customers' needs and to develop new customer services. "Creativity" is the ability to explore innovative approaches to meet goals and come up with creative solutions. "Flexibility" is the ability to adapt to changes in a timely manner by shifting the way they think and behave. "Practicability" is the ability to continue to achieve goals, regardless of any barriers. "Strategic thinking" is the ability to suggest strategic solutions to achieve organizational objectives even when problems arise. "Innovation" is the ability to seek new technology or tools required to carrying out tasks. "Understanding" is the ability to analyze information from different perspectives and to make necessary decisions effectively. "Marketing" refers to the overall activities in which a sales plan is established and various promotional tools are used to increase sales of agricultural products. In addition, customer complaints and opinions are tackled and solved immediately. "Getting information" is the ability to collect information needed by farmers through various means and achieve organizational objectives. "Management" is the ability to manage the operation properly in response to changes, as well as maximizing production.

In model 2 , the independent variables were divided into basic and professional competence of extension workers. Basic competence, which is essentially required to perform any kind of job or task, included "self-development", "conflict resolution", "problem solving", "flexibility", "interpersonal skills" and "research and analytical skills".

Professional competence was defined as the ability to carry out crucial extension work, but that was not significant in performing other tasks. Professional competence included "strategic instruction", "management of extension works", "agricultural extension", "customer orientation" and "technical expertise".

"Self-development" is the ability to keep learning steadily to increase the level of professionalism. "Conflict resolution" is the ability to resolve conflict and disputes within agricultural organizations quickly and peacefully. "Problem solving" is the ability to solve problems effectively in a creative and logical manner. "Flexibility" is the ability to adapt to changes in a timely manner by shifting the way they think and behave in extension work. "Interpersonal skills" is the ability to maintain a good working relationship with people or organizations involved in extension work. "Research and analytical skills" is the ability to collect, analyze and utilize information for extension work. 
Table 1. Variables used for the analysis

\begin{tabular}{lll}
\hline \multirow{2}{*}{ Description } & $\begin{array}{l}\text { Individual competence of farmers } \\
\text { and organizational performance }\end{array}$ & $\begin{array}{l}\text { Individual competence of extension workers and } \\
\text { organizational performance }\end{array}$ \\
\hline Control variables & $\begin{array}{l}\text { Attendance of training } \\
\text { Satisfaction with training } \\
\text { The systematization of farmers }\end{array}$ & $\begin{array}{l}\text { The extent of systematization of farmers in the area } \\
\text { Extension workers training experience and satisfaction }\end{array}$ \\
& - \\
The leadership in organization & - \\
Customer service & Self-development \\
& Creativity & Conflict resolution \\
& Flexibility & Flexibility \\
& Goal achievement & Interpersonal skills \\
& Strategic thinking & Research and analytical skills \\
& Innovative & Strategic instruction \\
& Understanding ability & Management of extension works \\
& Marketing & Agricultural extension \\
& Information collection & Customer Orientation \\
Management skills & Technical expertise \\
& Performance of agricultural & Performance of agricultural organizations in area of \\
& organizations to which they belonged & responsibility \\
\hline
\end{tabular}

Among the attributes of professional competence, "strategic instruction" is the ability to help set a strategic mission or goal for organizations in rural areas and to establish plans to achieve these goals. "Management of extension works" is the ability to manage various resources used for agricultural organizations efficiently. "Agricultural extension" is the ability to utilize various training methods in a timely and proper way when providing extension services. "Customer orientation" is the ability to utilize understanding about surrounding in extension worker's assignment area of agricultural organization for farmers. "Technical expertise" is the ability to use professional techniques and knowledge required by the qualification to meet the needs of agricultural organizations.

\subsection{Dependent Variable}

The performance of agricultural organizations was defined as the dependent variable. Quantitative indicators, such as revenue and net profit, were used to measure organizational performance in previous studies. However, this study adopted qualitative indicators, because it was difficult to compile revenue data from the various agricultural organizations. In addition, the revenue and net profit of agricultural organizations vary significantly within agricultural areas and breeds, making them difficult to compare. In addition, it is not feasible to compile data from small-sized farmers, which are prevalent in the Korean agricultural industry and to produce objective quantitative statistics.

This study measured the performance of farmers and extension (Extension workers are government employees working at agricultural institutions. They are responsible for assisting farmers in terms of lifestyle, farm management, and farming, and play a similar role to their counterparts in the U.S.) workers in the planning, execution, assessment and feedback phases, while they worked for agricultural organizations, using a sevenpoint Likert scale. Items asking for extension workers' income and occupational satisfaction were also added to measure organizational performance.

In model 1, the performance of farmers in each phase while they worked for their organizations was measured by means of the relevant items. In model 2, the organization performance of extension workers in each phase was combined with their income and occupational satisfaction to compute a mean value, which was then used in the analysis.

\subsection{Reliability Analysis (Cronbach's alpha Coefficient)}

The results of the reliability analysis for models 1 and 2 are described in Table 2 . The internal consistency of the instrument was acceptable, as items in model 1 had a Cronbach's alpha value of $\alpha=0.95$ or higher and those in model 2 showed a Cronbach's alpha value of $\alpha=0.90$ or higher.

\subsection{Result of Hierarchical Multiple Regression Analysis (Model 1)}

The results of the hierarchical multiple regression analysis of model 1 are shown in Table 3. The analysis contained control variables that related individual competence to organizational performance. 
Table 2. Results of reliability analysis

\begin{tabular}{|c|c|c|c|c|c|c|}
\hline \multirow[b]{2}{*}{ Description } & \multicolumn{3}{|l|}{ Model 1} & \multicolumn{3}{|l|}{ Model 2} \\
\hline & Variables & $\mathrm{N}$ & Cronbach's $\alpha$ & Variables & $\mathrm{N}$ & Cronbach's $\alpha$ \\
\hline \multirow[t]{4}{*}{ Control variables } & Attendance of training & 1 & - & $\begin{array}{l}\text { The extent of systematization } \\
\text { of farmers in the area }\end{array}$ & 1 & - \\
\hline & Satisfaction with training & 1 & - & & & \\
\hline & The systematization of farmers & 1 & - & Extension workers training & 3 & 0.954 \\
\hline & The leadership in organization & 1 & - & experience and their satisfaction & & \\
\hline \multirow{10}{*}{$\begin{array}{l}\text { Independent } \\
\text { variables }\end{array}$} & Customer service & 5 & 0.965 & Self-development & 3 & 0.952 \\
\hline & Creativity & 4 & 0.965 & Conflict resolution & 2 & 0.947 \\
\hline & Flexibility & 4 & 0.963 & Flexibility & 3 & 0.946 \\
\hline & Goal achievement & 5 & 0.964 & Interpersonal skills & 2 & 0.945 \\
\hline & Strategic thinking & 5 & 0.964 & Research and analytical skills & 3 & 0.944 \\
\hline & Innovation & 4 & 0.964 & Strategic instruction & 2 & 0.944 \\
\hline & Understanding ability & 3 & 0.965 & Management of extension works & 2 & 0.944 \\
\hline & Marketing & 4 & 0.964 & Agricultural extension & 3 & 0.943 \\
\hline & Information collection & 4 & 0.964 & Customer orientation & 2 & 0.943 \\
\hline & Management skills & 3 & 0.964 & Technical expertise & 2 & 0.944 \\
\hline Dependent variables & Organizational performance & 11 & 0.963 & Organizational performance & 13 & 0.943 \\
\hline
\end{tabular}

Table 3. Effects of individual competence of farmers on organizational performance

\begin{tabular}{|c|c|c|c|c|c|c|c|}
\hline & \multirow[b]{2}{*}{ Model } & \multirow[b]{2}{*}{$\mathrm{R}^{2}$} & \multirow[b]{2}{*}{$\Delta \mathrm{R}^{2}$} & \multicolumn{2}{|c|}{ Unstandardized coefficients } & \multicolumn{2}{|c|}{ Standardized coefficients } \\
\hline & & & & $\beta$ & Standard error & $\beta$ & $\mathrm{t}$ \\
\hline \multirow[t]{3}{*}{1} & (constant) & $0.518 * * *$ & & 1.204 & 0.492 & & 2.446 \\
\hline & Attendance of training & & & 0.310 & 0.102 & 0.346 & $3.030 * * *$ \\
\hline & Satisfaction with training & & & 0.430 & 0.113 & 0.437 & $3.820 * * *$ \\
\hline \multirow{5}{*}{2} & (constant) & $0.720 * * *$ & $0.201 * * *$ & 0.142 & 0.420 & & 0.339 \\
\hline & Attendance of training & & & 0.097 & 0.085 & 0.108 & 1.140 \\
\hline & Satisfaction with training & & & 0.198 & 0.094 & 0.201 & $2.105 * *$ \\
\hline & The systematization of farmers & & & 0.196 & 0.076 & 0.209 & $2.596 * *$ \\
\hline & The leadership in organizations & & & 0.463 & 0.089 & 0.483 & $5.204 * * *$ \\
\hline \multirow[t]{15}{*}{3} & (constant) & $0.861 * * *$ & $0.142 * * *$ & -1.233 & 0.375 & & -3.283 \\
\hline & Attendance of training & & & 0.051 & 0.077 & 0.057 & 0.663 \\
\hline & Satisfaction with training & & & -0.051 & 0.084 & -0.052 & -0.614 \\
\hline & The systematization of farmers & & & 0.211 & 0.066 & 0.224 & $3.207 * * *$ \\
\hline & The leadership in organizations & & & 0.274 & 0.077 & 0.286 & $3.539 * * *$ \\
\hline & Customer satisfaction & & & 0.279 & 0.100 & 0.258 & $2.795 * * *$ \\
\hline & Creativity & & & -0.035 & 0.101 & -0.033 & -0.348 \\
\hline & Management & & & 0.316 & 0.173 & 0.254 & $1.821 *$ \\
\hline & Practicability & & & 0.209 & 0.123 & 0.195 & $1.692 *$ \\
\hline & Flexibility & & & -0.080 & 0.131 & -0.072 & -0.614 \\
\hline & strategic thinking & & & -0.057 & 0.141 & -0.051 & -0.406 \\
\hline & Innovation & & & 0.303 & 0.131 & 0.278 & $2.305 * *$ \\
\hline & Understanding & & & -0.057 & 0.137 & -0.053 & -0.417 \\
\hline & Getting information & & & -0.164 & 0.138 & -0.161 & -1.188 \\
\hline & Marketing & & & 0.009 & 0.102 & 0.008 & 0.085 \\
\hline
\end{tabular}

Notes: $* \mathrm{p}<0.1, * * \mathrm{p}<0.05, * * * \mathrm{p}<0.01$

The first sub-model $(\mathrm{F}=37.663, \mathrm{p}<0.001)$ used control variables (attendance of training and satisfaction with training) as independent variables, as they indicated the prior experience of farmers. In addition, the performance of agricultural organizations was a single dependent variable.
The second sub-model $(\mathrm{F}=24.499, \mathrm{p}<0.001)$ contained the controlled variables satisfaction with training and attendance of training. Additional control variables (the systematization of farmers and the leadership in organizations) were added as independent variables to the model. 
The third sub-model $(\mathrm{F}=5.925, \mathrm{p}<0.01)$ was built by adding 10 attributes of competence as independent variables to the second sub-model. In sub-model $3,(\beta=$ $0.861, \quad(p<0.001)$, which means that $86.1 \%$ of organizational performance was explained by the independent variables. The addition of the 10 attributes of competence $(\beta=0.142, p<0.001)$ led to a $14.2 \%$ increase in explainable variance in the dependent variable.

The independent variables applied to sub-model 3, namely customer satisfaction $(\beta=0.279, \mathrm{p}<0.01)$, management $(\beta=0.316, \mathrm{p}<0.1)$, practicability $(\beta=$ $0.209, p<0.1)$, innovation $(\beta=0.303, p<0.05)$, exhibited a significant positive correlation with organizational performance. Of those, management had the most significant effect on performance of agricultural organizations, followed by innovation, customer satisfaction and practicability.

In the same model, the control variables (attendance of training and satisfaction with training) did not have a statistically significant effect on the dependent variable. However, other control variables (the systematization of farmers and the leadership in organizations) were significantly related. In particular, the effects of the systematization of farmers significantly rose in submodel 3 as compared to sub-model 2.

\subsection{Result of Hierarchical Multiple Regression Analysis (Model 2)}

The results of the hierarchical multiple regression analysis for model 2 are shown in Table 4.

Sub-model 1 was designed to relate the control variables "the extent of systematization of farmers in the area" to organizational performance.

In sub-model 2, the above variable was controlled and other control variables (extension workers training experience and satisfaction with training) were added to the sub-model.

Sub-model 3 explained which attributes of competence of extension workers were related to the performance of agricultural organizations in the area in which they work. Among the attributes describing the competence of extension workers, "interpersonal skills" $(\beta=0.137, \mathrm{p}<0.1)$, "research and analytical skills" $(\beta=$ $0.163, \mathrm{p}<0.05)$, "strategic instruction" $(\beta=0.327$, $\mathrm{p}<0.01)$, "agricultural extension" $(\beta=0.166, \mathrm{p}<0.1)$, "customer orientation" $(\beta=0.194, \quad \mathrm{p}<0.05)$ and "technical expertise" $(\beta=-0.169, \mathrm{p}<0.05)$ were statistically significant.

Table 4. Effects of individual competence of extension workers on organizational performance

\begin{tabular}{|c|c|c|c|c|c|c|c|}
\hline & \multirow[b]{2}{*}{ Model } & \multirow[b]{2}{*}{$\mathrm{R}^{2}$} & \multirow[b]{2}{*}{$\Delta \mathrm{R}^{2}$} & \multicolumn{2}{|c|}{ Unstandardized coefficients } & \multicolumn{2}{|c|}{ Standardized coefficients } \\
\hline & & & & $\beta$ & Standard error & $\beta$ & $\mathrm{t}$ \\
\hline \multirow[t]{2}{*}{1} & (constant) & $0.541 * * *$ & & 1.218 & 0.356 & & 3.421 \\
\hline & $\begin{array}{l}\text { The extent of systematization of } \\
\text { farmers in the area }\end{array}$ & & & 0.643 & 0.064 & 0.735 & $10.067 * * *$ \\
\hline \multirow[t]{3}{*}{2} & (constant) & $0.591 * * *$ & $0.050 * * *$ & 1.031 & 0.343 & & 3.006 \\
\hline & $\begin{array}{l}\text { The extent of systematization of } \\
\text { farmers in the area }\end{array}$ & & & 0.544 & 0.068 & 0.623 & $8.014 * * *$ \\
\hline & $\begin{array}{l}\text { Extension workers training } \\
\text { experience and satisfaction } \\
\text { with the training }\end{array}$ & & & 0.159 & 0.049 & 0.25 & $3.220 * * *$ \\
\hline \multirow[t]{13}{*}{3} & (constant) & $0.869 * * *$ & $0.278 * * *$ & 0.149 & 0.268 & & 0.555 \\
\hline & $\begin{array}{l}\text { The extent of systematization } \\
\text { of farmers in the area }\end{array}$ & & & 0.195 & 0.062 & 0.223 & $3.160 * * *$ \\
\hline & $\begin{array}{l}\text { Extension workers training } \\
\text { experience and satisfaction } \\
\text { with the training }\end{array}$ & & & 0.046 & 0.033 & 0.072 & 1.395 \\
\hline & Self-development & & & -0.059 & 0.044 & -0.072 & -1.341 \\
\hline & Conflict resolution & & & -0.078 & 0.060 & -0.081 & -1.296 \\
\hline & Flexibility & & & 0.083 & 0.074 & 0.078 & 1.119 \\
\hline & Interpersonal skills & & & 0.138 & 0.076 & 0.142 & $1.826^{*}$ \\
\hline & Research and analytical skills & & & 0.163 & 0.080 & 0.179 & $2.047 * *$ \\
\hline & Strategic instruction & & & 0.324 & 0.067 & 0.397 & $4.832 * * *$ \\
\hline & Management of extension works & & & -0.099 & 0.067 & -0.118 & -1.483 \\
\hline & Agricultural extension & & & 0.169 & 0.082 & 0.189 & $2.075^{*}$ \\
\hline & Customer orientation & & & 0.195 & 0.086 & 0.212 & $2.273 * *$ \\
\hline & Technical expertise & & & -0.168 & 0.078 & -0.192 & $-2.160 * *$ \\
\hline
\end{tabular}

Notes: $* \mathrm{p}<0.1, * * \mathrm{p}<0.05, * * * \mathrm{p}<0.01$ 
Table 5. Attributes of competence to be strengthened

\begin{tabular}{lll}
\hline \multirow{2}{*}{$\begin{array}{l}\text { Description } \\
\text { Independent variables }\end{array}$} & $\begin{array}{l}\text { Competence of farmers (internal factors) } \\
\text { needed to improve organizational performance }\end{array}$ & $\begin{array}{l}\text { Competence of extension workers (external factors) } \\
\text { needed to improve organizational performance }\end{array}$ \\
& Customer satisfaction & $\begin{array}{l}\text { Interpersonal skills } \\
\text { Research and analytical skills }\end{array}$ \\
& Management & Strategic instruction \\
& Practicability & Agricultural extension \\
& Innovation & Customer Orientation \\
\hline
\end{tabular}

Of these variables, "interpersonal skills", "research and analytical skills", "strategic instruction", "agricultural extension" and "customer orientation" showed a positive correlation with organizational performance in the area of responsibility.

However, "technical expertise" exhibited a negative correlation. The negative relationship of technical expertise was attributed to the fact that 54 extension workers were not involved in growing crops and 34 workers provided extension services for crop growing. Thus, the former group did not have much knowledge or skill in the area of crop growing.

Among the attributes describing basic competence, interpersonal skills and research and analytical skills were positively correlated, along with three attributes of professional competence.

\section{DISCUSSION}

Until now, previous studies have not addressed the relationship between farmer and extension worker competences and the performance of the agricultural organization to which they belong. Therefore, we compare our results to those of studies in other industries.

The study of Open Innovation Competence analyzed the association between competence and success of general innovation processes by surveying 73 open innovation professionals in the industries of agriculture, services, wholesale and retail and public. As a result, the competency "monitor" is significantly and positively linked to general innovation processes and the competences "compete", "handle conflicts" and "analysis" are significantly negative.

According to "the study of the effects of personal variables on the salesperson's performance", it was revealed that education level, sales experience, knowledge, direction for energy and judgment have significant effects on sales performance.

Farmer and extension worker competences can be strengthened to improve the performance of the organizations to which they belong.

As shown in Table 5, the results of the study support the need for strengthening those attributes of competence that are positively associated with organizational performance to create the synergy needed to boost the performance of agricultural organizations.

As indicated in this study, customer satisfaction, management, practicability and innovation can be developed and improved among farmers for the future growth of the agricultural sector.

At the same time, interpersonal skills, research and analytical skills and customer orientation should be nurtured among extension workers, as these attributes demonstrated a close correlation with organizational performance.

\section{CONCLUSION}

The Korean agricultural sector has sought to improve the performance of agricultural organizations using systematization of farmers as a way to foster agriculture competitiveness amid growing challenges. However, forming a cooperative unit among farmers and the active operation of such organizations has been sluggish for various reasons.

This study aimed to determine the relationship between the competence of farmers and extension workers and the performance of the agricultural organizations to which they belong. Thus, this study focused on individual competence and proposed improvements in organizational performance by strengthening those attributes of competence of the parties involved. This aim indicates a departure from the industry-wide effort to increase agricultural competiveness, which was explained above.

A hierarchical multiple regression analysis was performed to explain the association between the competence of farmers and extension workers and organizational performance. Here, "customer satisfaction", "management", "practicability" and "innovation" were found to be attributes of farmers' competence related to organizational performance.

In the extension workers group, "interpersonal skills", "research and analytical skills", "strategic instruction", "agricultural extension" and "customer orientation" were found to be associated with organizational performance. 
To maximize the performance of farmer organizations, the attributes of competence that showed a positive and statistically significant association with organizational performance need to be strengthened. These positively correlated attributes should also be boosted for extension workers, as they are involved in the performance of agricultural organizations as external impacts.

To have all parties increase their competence and therefore organizational performance, providing appropriate training programs and objectives for that training is likely imperative. This new angle on improving organizational performance in the agricultural sector may be an alternative solution to the current efforts, which have proved to be less successful than hoped.

There are two limitations of this study. Firstly, agricultural organization performance varied between regional groups. Secondly, even in the same regions, performance sometimes varied between items. Consequently, objective measurement was difficult.

For this reason, we measured the process performance of the agricultural organization management, which is a more subjective than quantitative criterion. Therefore, future studies should limit the regional scope and items measured to specifically measure farmer and extension worker competences and agricultural organization performance.

\section{ACKNOWLEDGEMENT}

This study was supported by Konkuk University.

\section{REFERENCES}

Chatenier, E.D., 2009. Open Innovation Competence. 1st Edn., Wageninegen University, Netherlands, ISBN10: 9085854423, pp: 200.

Churchill, Jr., G.A., N.M. Ford and O.C. Walker, Jr., 1976. Organizational climate and job satisfaction in the salesforce. J. Market. Res., 13: 323-332. DOI: $10.2307 / 3151014$

Heo, J.G., 2009. The Effects of Personal Variables on the Salesperson's Performance: The Case of Small and Medium-Sized Tool Distribution Firms. Anyang University, Korea.

Kim, Y.D., S.G. Kim, H.M. Kim and S.H. Chae, 2013. An impact analysis of famer's individual competency on agricultural organization's performance. J. Agric. Extens. Community Dev., 20: 143-172. DOI: 10.12653/jecd.2013.20.1.0143

Lee, H.K., 2002. Study of Required Competency. In: Human Resources which affects Organizational Performance, Lee, H.K. (Ed.), Chungang University, Korea.

Mu-Geun, O., 1987. A Study of Rural Development and Readership: In that Case of Chungcheongnam-do, Yesan-gun. Hankuk University of Foreign Studies, Korea.

Tiraieyari, N., A. Hamzah, B.A. Samah and J. Uli, 2013. Attitudes of Malaysian extension workers towards sustainable agricultural practices. Am. J. Environ. Sci., 9: 33-37. DOI: 10.3844/ajessp.2013.33.37 